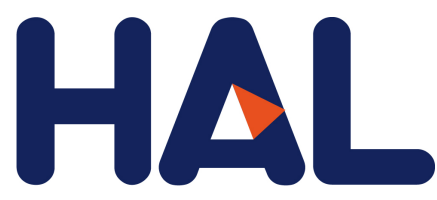

archives-ouvertes

\title{
Time Variation of Forces in a Synchronous Machine Using Electric Coupled Network Model
}

\author{
Michel Hecquet, P. Brochet
}

\section{To cite this version:}

Michel Hecquet, P. Brochet. Time Variation of Forces in a Synchronous Machine Using Electric Coupled Network Model. IEEE Transactions on Magnetics, Institute of Electrical and Electronics Engineers, 1998. hal-01713797

\section{HAL Id: hal-01713797 \\ https://hal.archives-ouvertes.fr/hal-01713797}

Submitted on 20 Feb 2018

HAL is a multi-disciplinary open access archive for the deposit and dissemination of scientific research documents, whether they are published or not. The documents may come from teaching and research institutions in France or abroad, or from public or private research centers.
L'archive ouverte pluridisciplinaire HAL, est destinée au dépôt et à la diffusion de documents scientifiques de niveau recherche, publiés ou non, émanant des établissements d'enseignement et de recherche français ou étrangers, des laboratoires publics ou privés. 


\title{
Time Variation of Forces in a Synchronous Machine Using Electric Coupled Network Model
}

\author{
M. HECQUET, P. BROCHET \\ L2EP \\ Ecole Centrale de Lille, Cité scientifique, B.P. 48, 59651 Villeneuve D’Ascq Cedex, FRANCE
}

\begin{abstract}
Radial forces between stator teeth and rotor claw inside a claw-pole alternator are investigated here. Typically three dimensional, the complete machine has been modelled as a coupled electric and magnetic circuit, with the aim of saving simulation time. Radial forces are obtained for several rotation speeds and stator currents. These results are compared with those of a 3D finite element analysis package, considered as reference results. A few typical results are also compared with measurements. Accuracy is sufficient to assess that the permeance network models, taking into account non linearities such as magnetic saturation, electronic commutations, and rotor movement, realise a good compromise between simulation time and precision.
\end{abstract}

Index-terms - coupled method, permeance network, clawpole alternator, magnetic forces, $3 \mathrm{~d}$ dynamic modelling.

\section{INTRODUCTION}

Currently, the finite element method (F.E.M.) gives very interesting results when studying rotating machines connected with electrical circuits, particularly magneticelectric coupled 2D versions [1], [2].

However, a large computation time is required : several hours on a work station; the use of FEM for a typical three dimensional (3D) machine will result in a prohibitive calculation time.

In order to address this problem, we propose a modelling approach based on a magnetic and electric coupled network.

Firstly, we shall account for the magnetic part with a permeance network, but these permeances are identified by 3D magnetostatic finite element calculations [3], [4]. It is the coupling of this network and the electrical circuits which is explained. This approach has already been tested and validated on one claw-pole alternator [5] using two different machines [6], [7].

Secondly, the results of computing magnetic forces for several speeds are presented. These results are compared with those obtained by 3D magnetostatic finite element calculations, but only on a subset of simulation points, because of the large simulation time required by the F.E. analysis [8].

In conclusion, we demonstrate that it is possible to quickly obtain the temporal variation of forces with a 3D permeance network model with good accuracy.

Manuscript received November 3, 1997

M. Hecquet, hecquet@ec-lille.fr, P. Brochet, brochet@ec-lille.fr, http ://www.univ-lille1.fr/l2ep/

\section{CLAW-POLE ALTERNATOR}

The particularity of this machine is that the field winding is composed of only one excitation coil enclosed by two pole wheels, or claw-pole, as shown in Figure 1. The flux concentration is greater in the claw-pole base, resulting in an axial flux machine called 'Modified Lundell Alternator'.

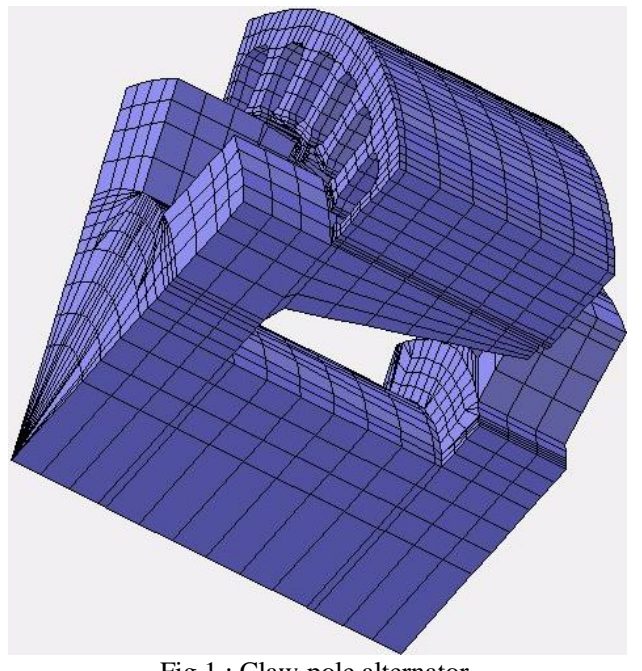

Fig. 1 : Claw-pole alternator.

\section{3D PERMEANCE NETWORK}

The magnetic circuit of the machine is modelled by a bounded permeance network taking into account geometrical symmetry. Each part of the magnetic circuit is represented by its permeance [9]. The network topology is chosen according to geometrical considerations based on knowledge of the general direction of the flux tubes. To achieve this goal, a 3D magnetostatic finite element analysis is used to get the main and leakage permeances.

The network is determined for different operating conditions. Its size is kept to a minimum while still containing a topology capable of giving accurate results. Another topology is presented by [10], [11]. A greater number of permeances or capacitors are defined and a better accuracy is obtained but the computing time is increased.

The determination of permeance network by our approach is different and is detailed in the following part. The magnetic circuit permeances are computed for materials with linear permeability but, in the simulation, a saturation effect is included using flux depending permeances, following the given $\mathrm{B}(\mathrm{H})$ curve of the material and using the 
relation (1) [12] :

$$
\nu_{r}=\frac{1}{\mu_{r}}=\varepsilon+(\mathrm{c}-\varepsilon) \frac{\mathrm{B}^{2 \alpha}}{\mathrm{B}^{2 \alpha}+\tau}
$$

Hence, we obtain a permeance network for each armature of the alternator. Figure 2 shows an example of part of a permeance network of the claw-pole. The transversal permeance $P_{\mathrm{amr}}$ is essential to take into account the armature magnetic reaction.

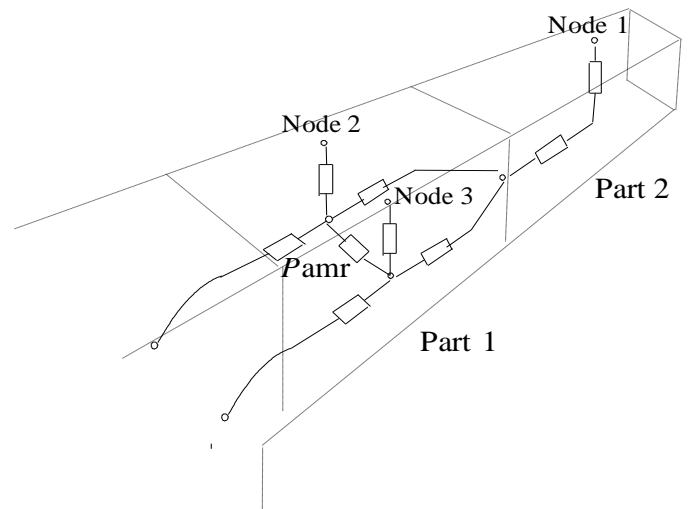

Fig.2: A claw-pole permeance network.

\section{A. Air-gap permeance}

The air-gap permeance located between a stator tooth and a rotor node, shown in Figure 2, is defined to take into account rotor movement. The evolution of air-gap permeance with mechanical angle $\theta$ is established using 3D magnetostatic finite elements for several positions of the stator and the rotor.

This calculation can be done automatically using a subroutine in the 3D package [4]. This gives the value of airgap permeance for different rotor positions. Then, a trigonometric interpolation is used to obtain a continuous law, as shown in Figure 3.

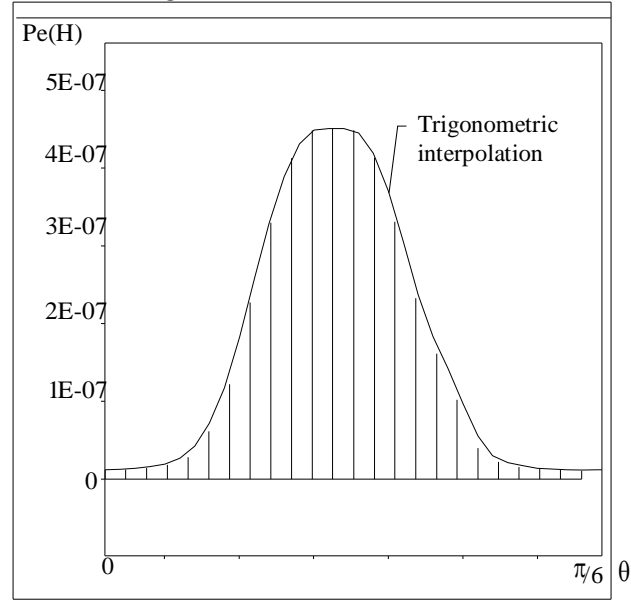

Fig.3: Evolution law of the air-gap permeance.

In this way, the permeance network is determined. Next, the coupling of this network with the electric circuits is detailed.

\section{B. Electric and magnetic coupling}

The alternator, with a direct voltage in the rotor coil and a constant rotor speed, produces three-phase alternating voltages. The electromotive forces (e.m.f.) of the stator are calculated with the well-known relation (2) for each phase:

$$
\mathrm{V}_{\mathrm{k}}=\mathrm{N}_{\mathrm{s}} \sum_{j} \frac{d \varphi_{j}}{d t}
$$

with $\varphi_{j}$, the flux flowing through the coil $\mathrm{j}$ and Ns, the number of turns stator coil.

The three-phases are connected to a six diode rectifier and a load. The alternator produces three alternating currents which are the origin of the magnetomotive forces in magnetic circuit of the stator. To establish the relationship between the electric current and the magnetomotive forces in the stator, a closed loop around the slot is considered, as shown in figure 4. A magnetomotive force $\left(F_{i}\right)$ is associated to each tooth (i).

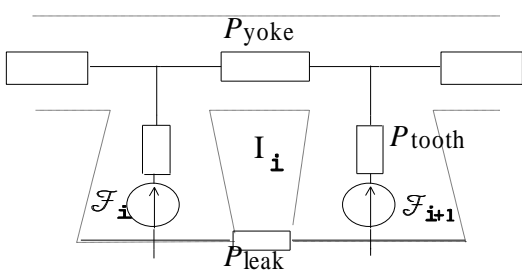

Fig.4: Closed contour around the slot.

Finally, using magnetic and electric laws, a system of equations (3) for calculating the magnetomotive forces is derived :

$$
\begin{aligned}
& \oint \stackrel{\square}{\mathrm{H}} \cdot \mathrm{dl}=\mathrm{N}_{\mathrm{s}} \mathrm{Ii}=\sum_{\mathrm{j}} \frac{\varphi \mathrm{j}}{P \mathrm{j}} \\
& \sum_{\mathrm{j}} \frac{\varphi_{\mathrm{j}}}{\mathrm{P}_{\mathrm{j}}}-F_{(\mathrm{i})}+F_{(\mathrm{i}+1)}=0 \\
& F_{(\mathrm{i}+1)}-F_{(\mathrm{i})}=-\mathrm{N}_{\mathrm{s}} \mathrm{I}_{\mathrm{i}} \quad \mathrm{i}=1, \mathrm{ne}_{\mathrm{e}} \\
& \text { (ne }=\text { tooth number) }
\end{aligned}
$$

This gives ne equations which are not linearly independent. For the final slot, the last equation is replaced by the law:

$$
\sum_{\mathrm{i}=1}^{\mathrm{ne}_{\mathrm{e}}} F_{\mathrm{i}}=0
$$

Hence, a complete model is obtained : the supply, the magnetic circuit with the air-gap permeances, and the load. A part of the 3D permeance network is represented in Figure 5 .

\section{SiMULATION RESULTS}

Firstly, the results presented are typical. Figure 6 shows the plot of the phase stator flux under no-load versus rotor field current obtained by simulation and experiment. 


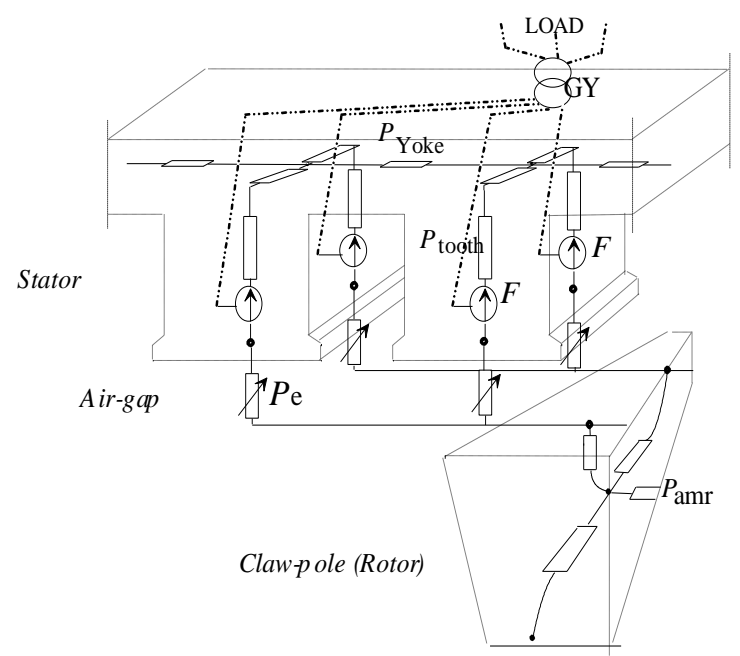

$P \mathrm{e}$, the air-gap permeances, $F$, the magnetomotive force source, $P$ amr, the armature magnetic reaction and GY, the element of coupling stator and load.

Fig.5 : 3D permeance network.

The low discrepancy between the simulation and the experiment is very encouraging and shows that the permeance network takes into account nonlinearities such as saturation.

In a second experiment, stator phases are connected to a load resistor through a rectifier composed of six diodes. In figure 7, the computed stator electromotive forces and the experimental measurement are compared for a load resistor current (Ich) of 45A.

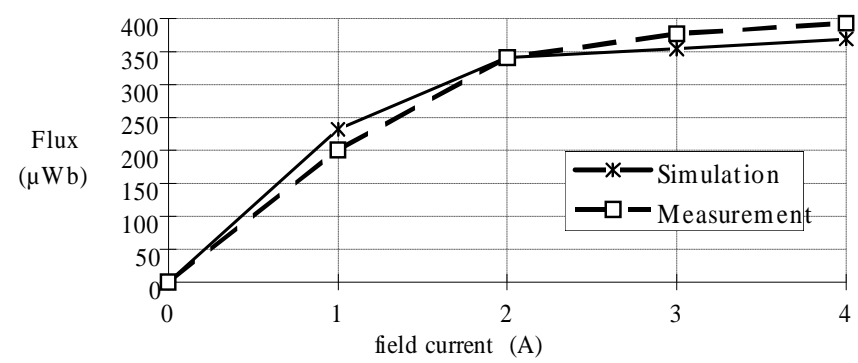

Fig.6: Stator flux phase at no-load versus rotor field current.
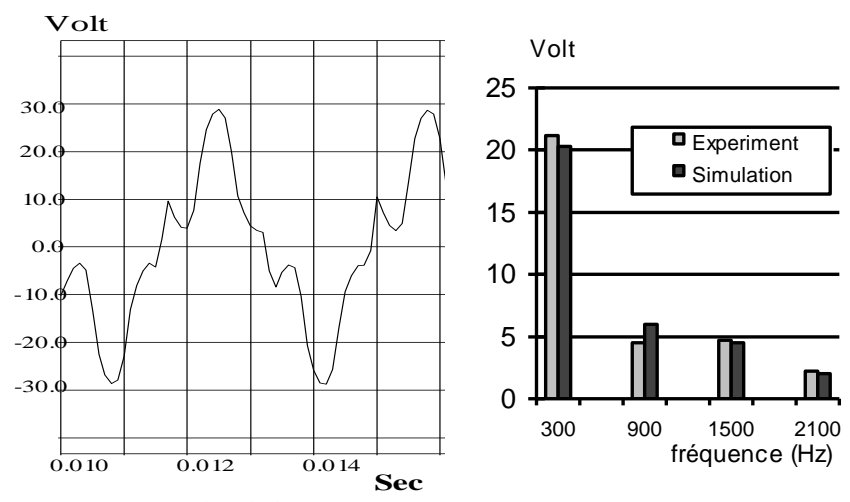

(Simulation)

Fig.7: Stator electromotive forces under load (Ich=45A).

The simulation results are very close to the experimental measurements. Further results in reference [7] demonstrate that this approach, the permeance network coupled with electric circuits, is quite interesting even if a few discrepancies appear. This is acceptable considering the simplicity of the model.

The model also gives electromagnetic torque[13] by the relation (5):

$$
\mathrm{C}=\frac{1}{2} \sum_{\text {Air-gap }} \boldsymbol{F}_{\mathrm{e}^{2}} \frac{\delta \boldsymbol{P} \mathrm{e}}{\delta \theta}
$$

where $\mathrm{Pe}$ are the air-gap permeances, and $\mathrm{Fe}$ the magnetomotive forces of these permeances.

The evolution of electromagnetic torque with the tooth effects, figure 8 , is obtained under the following conditions : Ich=45A., N=3000 rpm., Vr=13.5V (rotor supply).

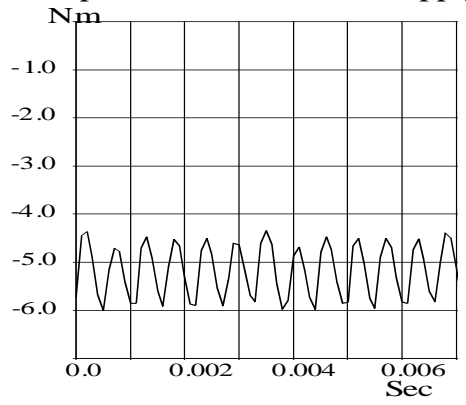

Fig. 8 : Calculated torque at $3000 \mathrm{rpm}$.

The simulated electromagnetic torque compares well with the average rotor torque which was measured to be $-6.5 \mathrm{Nm}$. The difference is due to the torque losses which were not taken into account in the simulation. The computing time is very small, one minute by period on an Alpha workstation.

One important possibility of the permeance network model is the ability to compute the magnetic forces applied to a stator tooth using these relations [13]:

$$
\begin{gathered}
\mathrm{F}_{\mathrm{r}(\mathrm{i})}=-\frac{1}{2} \sum_{\mathrm{j}=1}^{\mathrm{N}} \frac{\mathrm{B}^{2}(\mathrm{j}, \mathrm{i})}{\mu_{0}} \mathrm{~S} \\
\mathrm{~F}_{\mathrm{t}(\mathrm{i})}=\frac{1}{\mathrm{r}} \sum_{\mathrm{j}=1}^{\mathrm{N}}\left(\frac{1}{2} F^{2}(j, i) \frac{\delta \mathrm{P}(\mathrm{j}, \mathrm{i})}{\delta \theta}\right)
\end{gathered}
$$

with $\operatorname{Fr}(\mathrm{i})$ and $\operatorname{Ft}(\mathrm{i})$, the radial and tangential forces applied to the tooth (i), $\mathrm{B}(\mathrm{j}, \mathrm{i})$ and $F(j, i)$, the flux density and the magnetomotive force in the air-gap permeance (j) connected to the tooth (i), S the surface of the tooth (i), and $P(j, i)$, the air-gap permeances.

In figure 9, the evolution of radial forces applied to an half-tooth, obtained by coupled permeance network is compared with the 3D magnetostatic finite element calculations for no-load.

For the 3D magnetostatic finite element computation two methods have been used :

- Method 1 : radial forces are determined using the relation (8) of Maxwell tensor [4]

$$
\mathrm{F}_{\mathrm{X}}=\int\left(\frac{1}{\mu} \mathrm{b}_{\mathrm{X}}(\text { B.n })-\frac{1}{2 \mu}|\mathbf{B}|^{2} \mathrm{n}_{\mathrm{X}}\right)
$$

for a laminar surface in the air-gap under a tooth (i). 
The average radial force applied to this surface can be then obtained. This operation is repeated for different rotor positions.

- Method 2 : the average induction B on the same laminar surface is computed and $\operatorname{Fr}(\mathrm{i})$ is determined by the relation (6).

For radial force the simulation gives good results in comparison with the method 2 , but method 1 gives some disparities due to the different method of calculation.

For the force module, the disparity is due to the axial force which is not taken into account in this model.

In addition, the chamfer introduces a disymmetry, as shown figure 9.

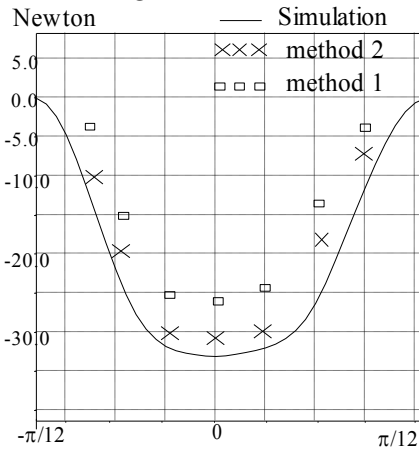

radial force

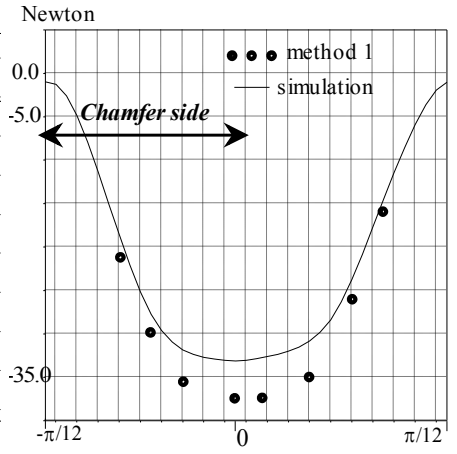

force module
Fig.9: Comparison of the force evolution under no-load applied to an half-tooth

In conclusion, the coupled permeance network gives radial forces and tangential forces with an excellent compromise between computing time and accuracy of results.

This is obviously advantageous if the goal is to determine the radial force evolution for different speeds, as in figure 10, and for different stator currents, as in figure 11.

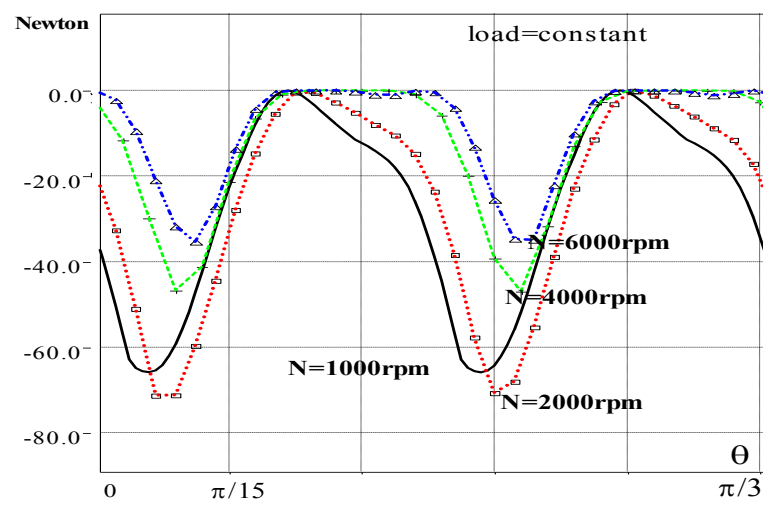

Fig. 10 : Radial forces applied to a tooth (under no-load).

The influence of the armature magnetic reaction can be seen in these figures. The maximum value of radial forces is found at the lower speed of $2000 \mathrm{rpm}$ because there is less armature reaction at this speed. In comparison with the study presented by [8], the advantage is the very small computing time, two minutes by period for the figures 10 and 11 with the alpha workstation, which allows on optimization process of this type of 3D machine.

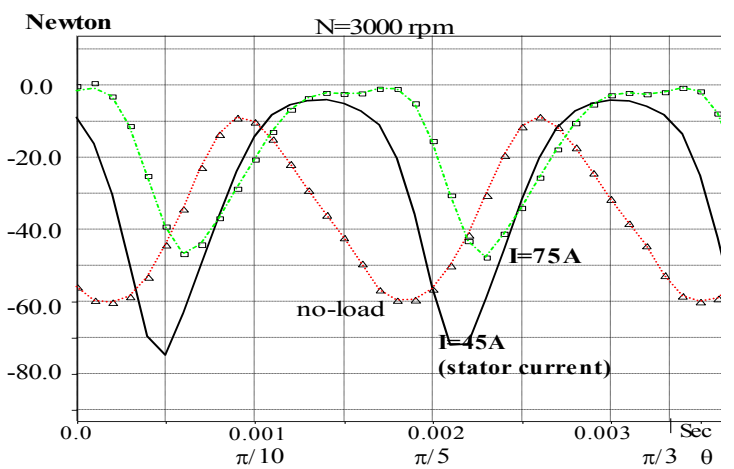

Fig. 11 : Radial forces applied to a tooth (under no-load).

\section{CONCLUSION}

The proposed approach, based on a permeance network connected to an electric network, has been successfully tested on a claw-pole alternator. Hence, it is possible to model 3D electromagnetic devices taking into account rotation with a much reduced computing time. In addition, the model easily gives the electromagnetic torque and radial forces applied to stator teeth which are necessary to determine or to reduce the electromagnetic noise, for example.

In future investigations, this approach will be used to optimize the claw-pole alternator and reduce radial forces.

\section{REFERENCES}

[1] S. Brisset, P. Brochet, "Numerical simulation of the transients of switched reluctance motor using an electronic-magnetic-mechanical coupled finite element model", ICEM 94, Paris, Proceeding Vol.2, Sept. 94, pp 402-407.

[2] F. Piriou and A. Razek, "Coupling of saturated electromagnetic systems to non-linear power electronic devices", Trans. IEEE on Magnetics, Vol. 24, pp 274-277, 1988.

[3] K.J.Binns, P.J.Lawrenson, C.W.Towbridge, "The analytical and numerical solution of electric and magnetic fields", J Wiley \& Sons, 1992

[4] Opera-3D, Vector Fields software, reference manual.

[5] M. Hecquet, P. Brochet, "Modelling of a claw-pole alternator using permeance network coupled with electric circuit", IEEE Trans. on agnetics, May 1995, Vol. 31, N³, pp 2131-2134

[6] M. Hecquet, P. Brochet, "Validation of coupled electric permeance network on a claw-pole alternator", ICEM'96, 10-12 Sept 1996.

[7] M. Hecquet, P. Brochet, "Modelling a claw-pole alternator using a permeance network coupled with electric circuits", Journal of applied Physics. III, August 96, pp 1099-1116

[8] I. Ramesohl, G.Henneberger, S. küppers and W. Hadrye, "Three dimensional calculation of magnetic forces and displacements of a claw-pole generator ", IEEE Trans. on Magnetics, May 1996, Vol. 32, $\mathrm{N}^{\circ} 3$, pp1685-1688.

[9] V. Ostovic, "Dynamics of saturated machines", Springer-Verlag, 1989

[10] A.Demenko, "Equivalent RC networks with mutual capacitances for electromagnetic field simulation of electrical machine transients", IEEE Trans. on Magnetics, March 1992, Vol. 28, N², pp 1406-1409.

[11] J. Worotynski, Turowski M., and Mendrela E.A., " The accuracy of calculation of magnetics fields, inductance and forces in electromagnetic devices using the reluctance network method ", Proc. ISEF'93, Warsaw, 1993, pp159-162.

[12] F. Hecht, A. Marrocco, "A finite element simulation of an alternator connected to an non-linear external circuit", IEEE Trans. Magnet., Vol.26, pp. 964-967, 1990

[13] M. Hecquet, " Contribution à la modélisation des systèmes électrotechniques par la méthode des schémas équivalents magnétiques. Application à l'alternateur automobile", Thèse de doctorat, Université des sciences et techniques de Lille, Janvier 1995 
